\title{
Multiple Intelligences and the Future of Education in Mexico
}

\author{
José G. Vargas Hernández \\ MBA, Ph.D. \\ Research Professor, member of the National System of Researchers \\ Department of Marketing and International Business \\ University Center for Economic and Administrative Sciences U of G. \\ Peripherals Norte 799 Building G-306 \\ Zapopan, Jalisco CP 45,100; Mexico \\ Tel: 52-(33)-3770-3343 ext 5097
}

E-mail: josevargas@cucea.udg.mx, jgvh0811@yahoo.com, jvargas2006@gmail.com

\author{
Mohammad Reza Noruzi \\ Executive Master Business Administration, EMBA \\ Islamic Azad University, Kaleibar, Iran \\ Faculty of Humanity Sciences, Department of Management and Accounting \\ Young Researchers Club Member, IAU Bonab, Iran \\ Tel: 98-426-4224915 E-mail: mr.noruzi.pnu@gmail.com \\ Narges Sariolghalam \\ Applied Mathematics, Faculty of Mathematics \\ Payam e Noor University of Maragheh, Iran \\ Tel: 98-421-2275121Ｅ-mail: n_ghalam@yahoo.com
}

\begin{abstract}
Higher Education in Mexico should try to respond to international standards and the dynamics of economic globalization processes. Competition in higher education systems will be increasingly global, so it is necessary to transform business processes. The implications of the relevance of higher education in a world under economic globalization processes are bounded by the requirements of competence necessary to conduct global market activities, languages and communication systems and information, and so on. As a result of these changes new players will come and a new model of management in universities.

This paper aims to analyze the prospects of education in Mexico under a consideration of major changes in the economic, political and social in 2020. This paper studies the governance of education, higher education policy, multiple intelligences, science and technology, the proposed institution of higher education, science and technology of the future, knowledge generation and innovation, linking, finance and comprehensive assessment of the educational process. Also the multiple intelligences notion comes as well.
\end{abstract}

Keywords: Higher education, Mexico, Multiple intelligences, Educational policy, Educational foresight

\section{The environment}

The dynamics of the processes of economic globalization that threatens the interpersonal relationships in all forms of social coexistence requires as an imperative, a moral review of the responsibilities of different actors, from a global ethic. The globalization of higher education is detrimental and beneficial consequences in higher education, for example, lack of adjustment of universities, curricula, poor quality, etc. In the consolidation of the HEI enters as an important factor to consider new international division of academic work, especially in the production of science and technology and preparation of senior cadres of scientists to produce advanced knowledge. 
Besides the companies generate and transmit information and knowledge, those who join the knowledge economy, record, market, import, export and apply knowledge by eliminating the traditional barriers between manufacturing and services. These knowledge-based economies are more competitive because of the added value offered by the systems of research and scientific and technological innovation.

However, rapid scientific advances, especially those in information technology and communications coupled with the increasing economic globalization processes, they need to review and reconsider these assumptions as a requirement of a state policy on public higher education, science and technology, a structural perspective and long-term, if one wants to answer the growing demands of Mexican society of the XXI Century. The evolving role of the state involves re-engineering processes to design new roles in education, research and technological development. The Mexican state should continue to keep the active regulation of the IES by strengthening market mechanisms and the promotion of linking the company to stimulate academic and scientific output.

Herrera (2002) explained that the urgency of institutional transformation in higher education lies in the convergence of forces such as the international trend determined by the impact of globalization and scientific-technological revolution of the late twentieth century, the approach national education policies that are very receptive to the recommendations of multilateral agencies seeking process, in most cases which cause reforms leading to improved quality, coverage and relevance within the traditional, disciplinary, bureaucratic and hierarchical in our country.

Institutional change will bring about change in the paradigm of the educational model in a way which involves the questioning of the societal model in which it is based and leading universities to other ways of thinking, organizing, producing and transmitting knowledge (Lanz, 2003).

The future of Mexican generations already predetermined by a set of neoliberal policies under a vision of global integration processes.

The scene of the most viable economic component is the trend to continue at current levels of uncertainty, crisis and possible economic growth rates moderate. With respect to labor market and employment, provides an accelerated growth of the services sector with a higher population in this segment, and lower growth of industrial and primary sectors. The trend towards outsourcing of the economy as a company focused on information and knowledge will impact on the profiles of professional scientific and technological training. Economic changes in the global scenario has serious repercussions on the labor market and changes in this frontier. The environmental changes are pushing for the transformation of higher education system.

ANUIES (1999) made the diagnosis of the problems of higher education in Mexico in a prospective for 2020 with a proposal for immediate action to boost higher education system. In terms of national and regional development and the role of government, the scenario of 2020 is a model for consultation and coordination with a flexible and decentralized state system of innovation and interaction between firms, markets, governments and universities.

In the demographic component, CONAPO projections indicate that population growth will diminish over the next five decades: by 2010 the population would range from 111.3 million inhabitants and 116; for 2020 at 119.7 to 130.5, for 2030 of 124.4 to 142.2 and for 2050 from 122 to 152.2 (p. 15). The applicant population growth of higher education, from 15 to 64 , increases to reach 80.8 million by 2031 and then dropped gradually. For the specific age group of higher education (16 to 22 years) is projected to grow until 2010 to fall from 2025, which implies that we should meet with the creation of new universities. An urban sprawl will have adverse consequences in HEIs. The population dynamics underpinning the challenge of covering higher education hinders the improvement of quality.

\section{Governance in education}

Higher education institutions should expand democratic procedures and clearly defined powers and functions limited. It is necessary to design higher education institutions to integrate the national education system and to react in diversified, flexible and relevant forms of social groups that have traditionally been excluded from the possibility of obtaining a high quality education and good quality. The IES in the coming years will continue to play an important social role that will make space for new additions to confront their emerging social paradigms, ideologies and power structures.

Institutional reforms to the system of higher education in Mexico require outreach strategies, scale, coverage and depth in the processes of institutional change. The reforms of higher education institutions will continue reorienting using the criteria of quality, relevance and internationalization.

The creation of forms of government and organization of HEIs while focusing on economic efficiency, more effectively in social development will remain a major challenge especially because new strategies are required for 
the generation and application of knowledge when changing the paradigms of scientific and technological higher education. New forms of government and legislation of the IES must be consistent with the challenges of economic globalization processes and the revolution in information technology and communications.

Also, decision-making processes must be open to more democratic processes, by strengthening flatter structures, use of information and communication technologies on end and behavior subject to processes of transparency and accountability. The diversification of institutional structures is manifested in a variety of organizational forms to provide care through programs and curricula to the needs of education, science and technology. The decision-making processes should be transparent, providing horizontal and inclusive openness to all stakeholders, but especially teachers, researchers and students, the main players in the processes of teaching and learning.

The creation and maintenance of state networks, regional, national and international help to make more efficient use of resources to provide innovative educational services of high quality, coverage and relevance. The quality of education is understood in a multidimensional way to understand the quality of teaching, management, academic programs, students, etc.. The National Development Plan (2006-2012) meant by quality of the education system, a multidimensional variable that combines access, equity, relevance and educational outcomes', the plan sets out strategies for cross-sectoral and strengthen the processes of learning assessment, teacher performance and school management.

Substantially improve the quality of higher education basing themselves on the improvement of graduate teachers, and in exercise of the National Assessment and Accreditation. It is intended that by 2020 the system is consolidated national planning and evaluation, accreditation and quality assurance in higher education.

\section{Multiple Intelligences Based Learning System, the Necessity of the Future Education in Mexico}

Background of Multiple Intelligences

There are different approaches to understanding intelligence. The psychometric view is the most traditional one. According to this approach, there is a single intelligence, which is often called general intelligence. Every individual is born with a certain intelligence or potential intelligence, which is difficult to be changed. Psychologists can assess one's intelligence (IQ) by means of short-answer tests and other purer measures such as the time it takes to react to a flashing light or the presence of a certain pattern of brain waves (Gardner, 2004). But the traditional IQ tests did not satisfy the researchers, so they developed a number of alternative theories, all of which suggest that intelligence is the result of a number of independent abilities that uniquely contribute to human performance. These theories suggest that rather than being fixed, unitary, and predetermined, intelligence is modifiable, multi-faceted, and capable of development (Gardner, 1993; Sternberg, 1986; Vygotsky, 1978; Yekovich, 1994; cited in Campbell, 2000, p. 8). Some of these theories have been summarized in the following paragraphs:

Robert Sternberg in his triarchic view of intelligence proposed three types of intelligence: 1) Componential Intelligence (analytical thinking): academic abilities to compare, evaluate and solve problems. 2) Experiential Intelligence (creativity and insight): the ability to invent, discover and theorize. 3) Practical Intelligence (street smarts): contextual abilities to adapt to the environment (Brown, 2000; Chastain, 1988). This theory of intelligence claims that intelligent behavior stems from a balance between analytical, creative and practical abilities and that these abilities function collectively to allow individuals to achieve success within particular socio-cultural contexts (Sternberg, 1988).

Gardner, in his MI theory, proposes that human intelligence has multiple dimensions that must be acknowledged and developed in education. He notes that traditional IQ or intelligence tests (such as Stanford-Binet test) measure only logic and language, but there are other equally important types of intelligence (Richrads \& Rodgers, 2001).

According to Gardner (1993), intelligence is a biopsychological potential. Intelligences cannot be seen or counted. They are used to process information and can be activated in a cultural setting to solve problems or create products that are of value in a culture. These potentials' activation depends upon the values of a particular culture, the opportunities available in that culture, and the personal decisions made by individuals and/or their families, schoolmasters, and others.

\section{Multiple Intelligences Theory}

Gardner's MI theory posits that human beings possess at least eight intelligences, to a greater or lesser extent. They are as follow (Armstrong, 2009, pp.6-7):

Once this broader and more pragmatic perspective was taken, the concept of intelligence began to lose its mystique and became a functional concept that could be seen working in people's lives in a variety of ways. Gardner 
provided a means of mapping the broad range of abilities that humans possess by grouping their capabilities into the following eight comprehensive categories or "intelligences":

Linguistic: The capacity to use words effectively, whether orally (e.g., as a storyteller, orator, or politician) or in writing (e.g., as a poet, playwright, editor, or journalist). This intelligence includes the ability to manipulate the syntax or structure of language, the phonology or sounds of language, the semantics or meanings of language, and the pragmatic dimensions or practical uses of language. Some of these uses include rhetoric (using language to convince others to take a specific course of action), mnemonics (using language to remember information), explanation (using language to inform), and metalanguage (using language to talk about itself).

Logical-mathematical: The capacity to use numbers effectively (e.g., as a mathematician, tax accountant, or statistician) and to reason well (e.g., as a scientist, computer programmer, or logician). This intelligence includes sensitivity to logical patterns and relationships, statements and propositions (if-then, cause-effect), functions, and other related abstractions. The kinds of processes used in the service of logical-mathematical intelligence include categorization, classification, inference, generalization, calculation, and hypothesis testing.

Spatial: The ability to perceive the visual-spatial world accurately (e.g., as a hunter, scout, or guide) and to perform transformations upon those perceptions (e.g., as an interior decorator, architect, artist, or inventor). This intelligence involves sensitivity to color, line, shape, form, space, and the relationships that exist between these elements. It includes the capacity to visualize, to graphically represent visual or spatial ideas, and to orient oneself appropriately in a spatial matrix.

Bodily-kinesthetic: Expertise in using one's whole body to express ideas and feelings (e.g., as an actor, a mime, an athlete, or a dancer) and facility in using one's hands to produce or transform things (e.g., as a craftsperson, sculptor, mechanic, or surgeon). This intelligence includes specific physical skills such as coordination, balance, dexterity, strength, flexibility, and speed, as well as proprioceptive, tactile, and haptic capacities.

Musical: The capacity to perceive (e.g., as a music aficionado), discriminate (e.g., as a music critic), transform (e.g., as a composer), and express (e.g., as a performer) musical forms. This intelligence includes sensitivity to the rhythm, pitch or melody, and timbre or tone color of a musical piece. One can have a figural or "top-down" understanding of music (global, intuitive), a formal or "bottom-up" understanding (analytic, technical), or both.

Interpersonal: The ability to perceive and make distinctions in the moods, intentions, motivations, and feelings of other people. This can include sensitivity to facial expressions, voice, and gestures; the capacity for discriminating among many different kinds of interpersonal cues; and the ability to respond effectively to those cues in some pragmatic way (e.g., to influence a group of people to follow a certain line of action).

Intrapersonal: Self-knowledge and the ability to act adaptively on the basis of that knowledge. This intelligence includes having an accurate picture of oneself (one's strengths and limitations); awareness of inner moods, intentions, motivations, temperaments, and desires; and the capacity for self-discipline, self-understanding, and self-esteem.

Naturalist: Expertise in the recognition and classification of the numerous species — the flora and fauna —of an individual's environment. This also includes sensitivity to other natural phenomena (e.g., cloud formations, mountains, etc.) and, in the case of those growing up in an urban environment, the capacity to discriminate among inanimate objects such as cars, sneakers, and CD covers.

Daniel Golman introduced the concept of Emotional Intelligence (EI). He claimed that efficient mental or cognitive processing is necessary for controlling even a handful of core emotions- anger, fear, enjoyment, love, disgust, and others. More to the point, Golaman compared the rational mind with the emotional mind. In comparing the rational mind with the emotional mind, Golman argued that the emotional mind is far quicker and acts without even pausing to consider what it is doing. He stated that the quickness of emotional mind prevents a deliberate, analytic reflection that is the sign of the thinking mind (Golman, 1995).

The theoretical framework of the present study is based on Gardner's MI theory. This theory has a positive and expansive view towards intelligence (Campbell, 2000).

\section{Developing MI}

Whether intelligence can develop depends upon three main factors (Armstrong, 2009, p.27):

1. Biological endowment - including hereditary or genetic factors and insults or injuries to the brain before, during, and after birth

2. Personal life history -including experiences with parents, teachers, peers, friends, and others who awaken intelligences, keep them from developing, or actively repress them 
3. Cultural and historical background-including the time and place in which you were born and raised and the nature and state of cultural or historical developments in different domains we can see the interaction of these factors in the life of Wolfgang Amadeus Mozart.

MI Strategies for Managing Individual Behaviors

\begin{tabular}{|c|c|c|c|}
\hline Intelligence & Aggressive Student & Withdrawn Student & Hyperactive Student \\
\hline Linguistic & $\begin{array}{l}\text { Bibliotherapy on theme of } \\
\text { anger management }\end{array}$ & $\begin{array}{l}\text { Taking up debate, oratory, } \\
\text { or storytelling }\end{array}$ & $\begin{array}{l}\text { Books on theme of } \\
\text { hyperactivity (e.g., The } \\
\text { Boy Who Burned Too } \\
\text { Brightly) }\end{array}$ \\
\hline $\begin{array}{l}\text { Logical- } \\
\text { Mathematical }\end{array}$ & $\begin{array}{l}\text { Dreikurs's logical- } \\
\text { consequences system }\end{array}$ & $\begin{array}{l}\text { Interactive computer } \\
\text { network, chess club }\end{array}$ & $\begin{array}{l}\text { Quantification of time } \\
\text { on task }\end{array}$ \\
\hline Spatial & $\begin{array}{l}\text { Visualizing ways of } \\
\text { managing conflict }\end{array}$ & $\begin{array}{l}\text { Movies on theme of } \\
\text { withdrawn child who } \\
\text { meets a friend }\end{array}$ & $\begin{array}{l}\text { Video games that help } \\
\text { develop focus and control } \\
\text { (neurofeedback) }\end{array}$ \\
\hline $\begin{array}{l}\text { Bodily- } \\
\text { Kinesthetic }\end{array}$ & $\begin{array}{l}\text { Role-play aggressive } \\
\text { behavior and try out } \\
\text { alternatives }\end{array}$ & $\begin{array}{l}\text { Pairing with trusted } \\
\text { person for walks, sports, } \\
\text { games }\end{array}$ & $\begin{array}{l}\text { Progressive relaxation, } \\
\text { yoga, hands-on learning, } \\
\text { strenuous exercise }\end{array}$ \\
\hline Musical & $\begin{array}{l}\text { Songs promoting social } \\
\text { skills }\end{array}$ & $\begin{array}{l}\text { Discography encouraging } \\
\text { connection with others }\end{array}$ & $\begin{array}{l}\text { Stimulating music } \\
\text { ("Musical Ritalin") }\end{array}$ \\
\hline Interpersonal & $\begin{array}{l}\text { Taking group class in } \\
\text { martial arts }\end{array}$ & Group counseling & $\begin{array}{l}\text { Leadership role in } \\
\text { cooperative learning group }\end{array}$ \\
\hline Intrapersonal & Time out, contracting & $\begin{array}{l}\text { One-to-one counseling/ } \\
\text { psychotherapy }\end{array}$ & Focusing exercises \\
\hline Naturalist & $\begin{array}{l}\text { Identifying with an animal } \\
\text { that can then learn how to } \\
\text { "tame itself" }\end{array}$ & $\begin{array}{l}\text { Introspective book about } \\
\text { nature involving friendship } \\
\text { (e.g., The Secret Garden) }\end{array}$ & Time in nature \\
\hline
\end{tabular}

Armstrong, 2009, pp.117-118

\section{The politics of higher education, science and technology}

The lines of education policy have a tendency to continuity and deepening of the National Development Plan (NDP) 2007-2012, which proposes an education based on educational change, with little input to overcome the limitations of the national education system (Observatorio Ciudadano de la Educación, 2007b). Under the concept of human development, the NDP aims to secure the Mexican meeting the education needs (NDP 200-2012:23) and recognized as a proposal for Project Mexico 2030, achieve a quality education with value formation and capabilities. The promotion of sustainable human development is guided by a focus on improving education and training as essential elements.

The processes of institutional transformation of higher education in Mexico involving powerful interest groups at local and federal governments in the formulation and implementation of strategies, as has been shown that each institution is a different case.

Expand the options available to the inhabitants of certain areas, whether you want to benefit the largely rural and indigenous people. The transformation of education is one of the challenges of equal opportunities in program development proposal of the NDP (2006-2012). The priorities are outlined in the general expansion of system to ensure educational opportunities for all people, removing economic exclusion, to computerize the national 
educational system, coordinate and decentralize and support for teaching through resources and training (Observatorio Ciudadano de la Education, 2007: 34).

Strategies for Education are located on the axes of the competitive economy and generate employment, equal opportunities and environmental sustainability. In the line of "high productivity growth, the policies suggested linking education and scientific and technological development with productivity, which paid little progress to increase as they have been limited investment by both the public and the private. In the last six years (2000-2006) was decreasing trend in the proportion of expenditure and GDP for the development of research and technology.

In the private sector contained Higher education institutions serving elite students from high income levels and high levels of academic quality on one hand and on the other, those universities that receive surplus unmet demand, which do not necessarily reach the average quality of the IES and which are also characterized by modest tuition fees. Perhaps the most important step which should give private education is to achieve territorial decentralization to increase its responsiveness to communities, villages and municipalities. The strong market orientations sebe not be cause for neglect of activities that investment by sources in its structure, not an immediate return (Altbch, 2002).

Among the assumptions of public higher education in Mexico, it is assumed as one of the state's social commitments with the characteristics of free, universal and secular. It is the responsibility of Mexican society demand that the State fulfills its functions to a viable long-term dimension, the higher education project to promote and achieve the conclusion of all efforts in a comprehensive and inclusive agreement of all sectors social.

The Mexican state will continue to ensure effective and making the social right of access to public education to all citizens who choose to continue on some of the institutions of higher education, science and technology, either public or private.

The social projection of present and future development of the IES should be guided by educational policies more consistent with the responsibilities arising from the economic reality and social policy of our people, ie educational policy with a full orientation of social policy. The XXI century Mexican society deposits in the institutions promoting knowledge certain responsibilities and expectations to which higher education institutions (HEIs), universities and technology cannot support others (Casanova Cardiel, 2007:36)

Achieving greater equity in income distribution in a country like Mexico where there is great inequality of income, represents a challenge that is related to economic growth and therefore the growth of educational provision to extend coverage opportunities. The national education project should ensure educational equity through mechanisms designed for educational federalism, but also must balance the equity with the involvement of school culture to the cultures of communities so as to strengthen intercultural education. The promotion of educational equity is to address target populations through the implementation of social policy cross-cutting strategies to support those most in need (Observatorio Ciudadano de la Educación, 2007).

The new education project is closely linked to the project of nation we want for Mexico. The new education project should be the result of a government policy sustained in the quality and competitiveness of the Mexican education system

\section{Draft Institution of Higher Education, science and technology to future}

The IES must be a university or a technologist with a project that goes beyond out into all areas of human development. The institutional complexity of the national education system is expressed in respect for the autonomy of universities makes it difficult to agreements to supplement resources.

Therefore, it requires institutional reform and consolidation on a framework that facilitates coordination and complementation rational and equitable use of resources and efforts of institutions of higher education, science and technology to achieve higher levels of development that meets the profiles regional. The discussion will focus on designing a model-oriented university more utilitarian sense of teaching and research in the design of a university model with a utopian project of democratic emancipation.

The IES implement programs for improvement in the quantity and quality of its infrastructure, environmental conditions and academic programs, with a parallel drive to stock assessment indicators. The criteria of quality, certification and accreditation of academic programs will be established by consolidated academic bodies in institutions of higher education, science and technology. The academic quality of programs of higher education, science and technology, is the condition to increase the certification processes and to guide the quantitative growth.

Institutional transformation has to further innovations in the academic model that takes into account the emergence of processes of economic globalization, scientific and technological changes are more advanced in the different areas of knowledge, the advancement of communication technologies and information. 
The ANUIES (1999) recommends following the strategies of planning and coordination to ensure the integration of higher education system. In 2020, the IES of Mexico will form a higher education system able to train professionals and senior researchers, generate and apply knowledge, expand and preserve culture. All these tasks are performed with quality, relevance, equity and amount comparable to international standards.

The strategies to implement institutional change in higher education should consider the many variables involved. Among the variables involved are highlighted in national educational policies and the maturity and bargaining power of institutional actors.

\section{Knowledge generation and innovation}

The quantitative scenarios registration, titling, coverage and general issues in higher education by 2020 , are determined by the conditions of inequality, inequity and social injustice. It requires an expansion of the education system as well as government initiatives and other sectors of the economy and society, to encourage recruitment of social demand and expand the coverage of the system.

You have to argue that the effort should focus on making the curriculum change, his times, teaching methods and techniques, the change must be addressed essentially the same content of the disciplines.

The ANUIES (1999) recommended in the years to achieve an open system of higher education against a closed, institutional networking, the use of information technology and communication for the formation of the virtual university, the grant legal personality to the rating agencies, and accrediting certifiers.

\section{Linking}

Leveraging the advantages of an information society and knowledge, the international mobility of academics, researchers and students will enhance the exchange of experiences, knowledge, skills, values and attitudes that will expand the horizons of vocational training. It is also important to promote programs linkage with multinational and global companies, not only to replenish the plans and programs of study but also to facilitate the employment of graduate immersion.

Institutional innovations to support the substantive functions of HEIs require better structures to expand services to business centers, business incubation programs, etc.. Not to mention the link with social and political sectors through programs such as ciberbolsas work, support groups and marginalized social exclusion, participation in specific projects of the three levels of government to promote regional and economic development, etc. .

\section{Finance}

The National Development Plan (2006-2012) is very brief to identify possible sources of funding and resources needed for education, research and technological innovation. Due to the high costs of higher education and scientific research and technological quality, new financing schemes will have serious repercussions on inter-relationships between HEIs and government authorities. These impacts would be reflected in the reduction of subsidies and budget allocations, in a more efficient exercise of spending and available resources.

The improvement in the rationale for allocating the financial resources to the various institutions of public education is crucial to abandon old practices articulated in international negotiations institutional political factors rather than partisan-centered rationality academic results. Therefore, in the coming years is to increase the quality of the processes of transparency and accountability of the substantive responsibilities of HEIs.

The IES must take concrete actions to increase transparency and accountability in the exercise and operation of public financial resources in a cohesive way with their university autonomy and other components of higher education systems in such a way that promotes collaboration complementarity institutional. The State should consider the investment in higher education and scientific research as social investment.

Increasing budgetary constraints financially pressuring higher education institutions in Mexico have impacted strongly on delivering quality education services in the public sector. The heavy tax burden that higher education represents for the Mexican state that can not meet all the expectations of scientific and technological training of Mexicans, has led to social transfer this responsibility to the private sector, not without difficulties for the huge infrastructure investments needed to provide educational services efficiently and effectively.

The quantitative growth of the private sector in education and research will result in higher recruitment of upper-class students by offering a higher leadership position, despite the heterogeneity. Many HEIs will travel paths for the conversion of public to private universities through market mechanisms their products, such as graduates, knowledge and values. 
Higher education requires a sustained effort to manage financial resources to meet the responsibilities for training, preservation of identity and values of culture, science and technology, knowledge generation, technological innovation, technology transfer etc. Transfer the responsibilities of financial contribution to private sector only partly resolve the complex problem because it limits opportunities for social mobility to those who need it because they can pay their training, so it is imperative that the State assume financial responsibility under a perspective long range to strengthen higher education in highly competitive sectors of society who lack the resources to do it by themselves.

The management of financial resources will become significant in the coming years which will require a greater deal of creativity To eke out scarce resources, and to new programs such as exploring linkages with other universities and foundations that have bags of funding for specific projects vocational training, creation of scientific and technological knowledge, technological innovation programs, technology transfer, support for disadvantaged groups to access to educational opportunities, etc..

In the coming years is to increase the management capacity to raise funds for financing, for example, by offering teaching activities, research, innovation, development and linkage to services can be classified as multiplier effects spill benefits to the students and researchers. One would expect that in the Mexico of the future, private initiative will increase their contributions, which would make them less dependent on progress in this area are conducted in more advanced countries.

The scarcity of financial resources and the urgent need for financing the activities of higher education, especially with regard to infrastructure and educational equipment will help us to generate resources from other sources such as the creation of trusts, institutional credit and income for themselves towards sale of services.

\section{Comprehensive assessment of the educational process}

The current National Development Plan (2006-2012) proposes the creation of the National System of Educational Evaluation in the middle and higher education and teacher performance measurement. In higher education, science and technology is a priority in the years to establish a comprehensive evaluation system of education is more focused on the evaluation of the entire educational process including the results.

The trend in assessment processes will continue in the mechanisms of the diagnostic evaluation of programs, evaluation of inputs, results of educational processes and formal accreditation system for independent bodies but with recognition of the education authorities. The assessment of institutional quality will encourage innovation by academic assessment results based on a funding model focuses on performance criteria and comprehensive programs of institutional strengthening.

This system should evaluate the performance of all actors involved in educational processes, including the State, community, education officials, teachers and researchers, parents, support institutions, students, etc. Similarly, the comprehensive evaluation system of the educational process should evaluate the institutions, infrastructure, financial resources and materials, resources and teaching aids, etc..

To achieve greater resource efficiency is necessary to implement assessment systems, accreditation and accountability for the application of resources. It requires policies, strategies, norms and performance indicators of academic quality and attention to environmental demands and the labor market. It is also important to disseminate the results of the evaluations, ensuring feedback to those involved in educational processes to establish appropriate remedial measures.

\section{Needs Action}

The remaining tasks proposed by De la Fuente (2007) to advance the knowledge society are: Investing in education, research and development, rede form a world-class university, raising the academic standards of the economically active population and import knowledge and not only export

The training of the future must be capable of combining pragmatic and empirical knowledge with theoretical and methodological knowledge. The reorganization of knowledge and their inter-disciplinary and interdisciplinary, relationship of curriculum and teaching-learning processes, and so on. Are urgent matters that the transformation of institutional academic management must address?

Higher education has as its main development challenges of educational content and curriculum plans from trans disciplinarily, complexity and uncertainty, methodological strategies, new forms of organization and government, creating strategic alliances for complementary resources, etc. The processing of HEIs in Mexico will face as a major challenge to respond in a more responsible to the demands of social and productive sectors. 
The challenges of higher education is to rethink its role and mission to establish alternative strategies for the future in a framework of sustainable development, peace culture and a global ethic. The challenges of educational reality require cooperation and solidarity as the foundations to avoid marginalization, fragmentation and polarization of knowledge.

Taking a critical discourse about the scope of the functions of the new model under the IES and a focus on market requirements underestimate the social needs of the Mexican state.

\section{References}

Altbch, Philip. (2002). Private higher education, UNAM / Group Editorial Porrua, Mexico.

ANUIES. (1999). The document "Higher Education in the XXI century. Lines strategic development. National Association of Universities and Institutions Higher Education. Mexico.

Armstrong, T. (2000). Multiple intelligences in the classroom. Alexandria, VA, USA: Association for Supervision. [Online] Available: http://site.ebrary.com/lib/modarres/Doc?id=10044795\&page=1 (July 18, 2007).

Armstrong, T. (2009). Multiple intelligences in the classroom. third Edition, Alexandria, Virginia USA.

Brown, H. D. (2000). Principles of language learning and teaching $\left(4^{\text {th }}\right.$ ed).San Francisco: Pearson Education.

Campbell, L. M. (2000). The unspoken dialogue: Beliefs about intelligence, students, and instruction held by a sample of teachers familiar with the theory of multiple intelligences. Unpublished doctoral dissertation, The Fielding Institute. United States.

Casanova Cardiel, Hugo. (2007). "University and Public Education: State responsibility, "Este País, No. 198, 35-38, September.

Chastain, K. (1988). Developing second language skills: Theory and practice (3rd ed). United States of America: Harcourt Brace Jovanovich.

De la Fuente, Juan Ramón. (2007). "University and Development", Este País, 197, August, p.12-14.

Gardner, H. (1993). Multiple intelligences: The theory in practice. New York: Basic Books.

Gardner, H. (2004). A multiplicity of intelligences: In tribute to Professor Luigi Vigno. [Online] Available: http://www.howardgardner.com/Papers/ documents/T-101\%20A\%20Multiplicity\%20REVISED.pdf (May 2, 2007).

Herrera, Alma. (2002). "The change in the nineties: a comparative study of public ten universities in Mexico, "in T. Didrikson, Axel and Alma Henderson (Ed.), The Transformation of Mexican University: ten case studies in the transition, Universidad Autonoma de Zacatecas / Grupo Editorial Porrua, Mexico, p. 9-10.

Lanz, Rigoberto. (2003). "What do you mean" university reform?: What people want they want reform, "mimeo, Caracas, March.

Llorens Baez, Luis."Feasibility of a higher education system in Mexico: Comments on the document "Higher Education into the Twenty-First Century.

Observatorio Ciudadano de la Educación. (2007). "A new educational model for XXI century Mexico? Education proposed by the SNTE "This Country 198, September, p.30-34.

Observatorio Ciudadano de la Educación. (2007b). "The" educational transformation" according to the National Development Plan 2007-2012 ", This Country 107, August, p.34-39.

Richards, J. C. \& Rodgers, T. S. (2001). Approaches and Methods in Language Teaching (2 ${ }^{\text {nd }}$ ed). Cambridge: Cambridge University Press.

Sternberg, R. J. (1986). What is intelligence? Norwood, NJ: Ablex.

Sternberg, R. J. (1988). The triarchic mind: A new theory of human intelligence. New York: Viking.

Vygotsky, L. S. (1978). Mind in society: The development of higher psychological Processes. Cambridge, MA: Harvard University Press.

Yekovich, F. R. (1994). Current issues in research on intelligence. Educational Resources Information Center Digest \#385605. 